\title{
Tradición e identidad en la música de concierto chilena
}

Tradition and identity in Chilean concert music

Jaime Vásquez ${ }^{1}$

UNIVERSIDAD ACADEMIA DE HUMANISMO CRISTIANO

El mestizaje, la síntesis musical, es un proceso de carácter permanente... (que) deja en evidencia cómo la intensificación del uso de informaciones sonoras gestadas en lo profundo de la sociedad americana, en concordancia con los acontecimientos sociopolíticos de cada instante, han incentivado dicho proceso de síntesis, contribuyendo así a crear productos culturales, en este caso musicales, reconocibles como chilenos $o$, al menos, como latinoamericanos. ${ }^{2}$

El año 1987, la agrupación chilena de compositores Anacrusa organiza en Chile en los salones del instituto Goethe, el Foro de Compositores del cono Sur en el cual participaron diversos compositores de países como Uruguay, Paraguay y Argentina, entre otros. Dentro de los participantes se encontraba el compositor nacional -radicado en EEUU- Juan Orrego Salas, quien para dar inicio al encuentro, propone una idea de identidad que dará las bases para avanzar hacia el tema central de la identidad latinoamericana:

“el artista busca a ciegas su propia identidad, la que sólo podrá evaluar a la luz de la creación resultante. ¿Y qué es lo que busca a ciegas?, ¿en qué podrá consistir aquello con lo cual se identifica? Yo creo que no es otra cosa que la asimilación de influencias que han ido ingresando a su mundo interior a lo largo de su vida, en virtud de una cadena de afinidades históricas, ambientales, familiares, sociales, geográficas, políticas, etcétera, y que en suma representan lo que llamamos una tradición" (OrregoSalas citado en Torres 38).

Orrego-Salas nos presenta la tradición como algo dinámico que se desarrolla y cambia a través de quienes la mantenemos y le damos expresión. Nosotros somos la tradición. En este

\footnotetext{
${ }^{1}$ Destacado compositor, arreglador e interprete musical en al área de la música popular moderna de fusión, experimental, como también en el área de la composición musical para teatro y Danza, en el ámbito Nacional e Internacional. Una de sus principales contribuciones las realiza como miembro del grupo rock alternativo/progresivo, jazz fusión y música experimental, FULANO.

${ }^{2}$ García, Fernando. Ponencia leída en el II Seminario "Instrumentos tradicionales - Músicas actuales, Santiago de Chile. 2004.
} 
sentido, el compositor musical no solo adhiere a usos tradicionales de su cultura, sino que aporta y la recrea desde su particularidad, reinterpretando y adaptándose a los cambios culturales, sociales y políticos: "la figura de compositor como el creador y transmisor de una serie de rasgos según su influencia y herencia, evoluciona y se mantiene en un constante cuestionamiento en lo que es lo más cercano a su realidad" (Castillo 4). Según esta idea ¿Como sería la figura del compositor latinoamericano que nos representaría? Para responder esta pregunta es necesario observar las bases estéticas del arte musical en Latinoamérica, donde se encuentran rasgos musicales de las tres Españas: la cristiana, la judía y arábigo-andaluza, de esas tres herencias surgen influencias que combinadas constituyen un cuerpo múltiple en el período colonial, donde podemos encontrar sonoridades europeas españolas fundidas con elementos autóctonos.

Por tanto, cuando hablamos de identidad latinoamericana "necesariamente habitamos los conceptos de diferencia y de mezcla. ¿Acerca de qué debería pronunciarse el artista latinoamericano para lograr ese anhelo representativo en su obra? La asunción de la mezcla entre lo propio y lo ajeno, ¿fortalecería esa búsqueda y el supuesto encuentro?” (Ibaceta 127). Siguiendo a este autor y sus inquietudes, vemos que habitamos un espacio común con una multiplicidad de formas y estilos que nos particularizan como territorios distintos, pero con herencia común. Esta complejidad ha guiado el hacer artístico de algunos compositores y artistas que sintiéndose parte de una herencia y una tradición, se reconocen como parte de una historia en desarrollo, que implica develar, recuperar, recrear, actualizar y proyectar.

Desde inicios del siglo XX aparecen compositores en Latinoamérica, que asumen la tarea de investigar en sus patrimonios musicales populares, folclóricos y vernáculos, logrando innovaciones sonoras que aportan al desarrollo de la composición en América, dentro de los cuales podemos nombrar algunos como Heitor Villalobos, Alberto Ginastera, Silvestre Revueltas, Carlos Isamitt, Roberto Falabella, Pedro Humberto Allende y Ortega, entre otros. Todos ellos comparten el uso de elementos musicales patrimoniales que aportan a sus creaciones, otorgándoles un sentido identitario que en un primer momento se ajustaba a una idea nacionalista y local de hacer arte; situación que posteriormente evoluciona hacia un americanismo musical el que surge como respuesta frente a una reflexión histórica de los creadores no solo de estos territorios americanos, sino del mundo entero, respecto de la identidad y la ancestralidad; desde esta idea los compositores americanos reflexionan su hacer como un aporte no solo a su espacio particular sino como un aporte al mundo musical en su totalidad. Como anécdota, cabe destacar que cuando PH Allende presentó sus Tonadas en Paris, Debussy comentó que estaban en presencia de una nueva música y no de una expresión local.

Sin embargo, situar a Latinoamérica como una propuesta y aporte a la cultura occidental genera una particular problematicidad, situación que vivimos al día de hoy quienes estamos en la realización artística con un compromiso identitario "el americano no (puede) seguir apoyándose en la cultura europea, sino que, al igual que el europeo tendrá que buscar nuevas soluciones, nuevos puntos de apoyo, y esto tendrá. que hacerlo por sí mismo (Chase 208). La tarea no acaba con tomar posición, sino que necesitamos llevar a la práctica compositiva la idea de americanismo musical. Así lo expresa Orrego Salas cuando habla del compositor que es arrastrado por un proceso de apoderarse de sí mismo, que le permite encontrarse y ser un genuino intérprete de su propio medio cultural y su época, como lo es el folclore y la música popular. (Orrego-Salas, citado en Torres, 1988).

En este contexto, de compromiso con la cultura y la política latinoamericana en Chile (recordemos entre los años 20 y 30, en coincidencia con la Revolución Mexicana, surge distintas explosiones sociales reivindicativas, tanto urbanas como rurales e indígenas, que no pasan 
desapercibidas para los artistas del continente y que a partir de los años 50 y 60, en el contexto de la revolución cubana, se aceleran las apuestas nacionalistas de la región), podemos encontrar obras como "La Suite Latinoamericana" de Luis Advis; "Américas" (1978) de Becerra; "Canto para Bolívar" de Orrego-Salas, entre otros. Este movimiento se conoció como "la vanguardia de los 60 ", la que condujo a los compositores chilenos a rutas sonoras nuevas, a través no solo de nuevas sonoridades musicales, sino que también en el uso de lenguas vernáculas y de instrumentaciones mixtas entre la orquesta tradicional y el folklore. Esto último lo encontramos por ejemplo en las cantatas populares de Advis, donde entre cellos, clarinetes y otros instrumentos de orquesta suenan tiples, bombos y quenas. Asimismo, se incursionó en el uso de instrumentos prehispánicos, como los utilizados en la obra "Elegía a Machu Pichu" (1965) de Celso Garrido Lecca. Estos usos se extienden hasta hoy en trabajos musical investigativos, como el que realiza el grupo la Chimuchina.

Este proceso de mestizaje musical ha estado entramado con los procesos políticos de nuestro país, no es menor el papel que cumplieron algunos compositores chilenos (Ortega, OrregoSalas, Advis, Lefever, Vila y otros) en la puesta en marcha del ideario politico del primer gobierno socialista elegido democráticamente en el mundo, liderado por el Dr Salvador Allende, situacion que se quiebra con la dictadura militar en el año 1973, y se retoma de alguna manera a fines del S. XX con compositoes como Guillermo Riffo en su "Ritual para la Tierra" (1988,) con elementos melódicos de la cultura Selknam; "El sur comienza en el patio de mi casa", (1996) de Rafael Díaz, con cantos Kawashkar; "Epigramas Mapuches" (1991) de Eduardo Cáceres; los trabajos de Carlos Zamora con elementos de la cultura atacameña; las creaciones de Gabriel Mathey o Juan Mouras sobre la cultura criolla; etc.

Considerando el panorama de la música de concierto en Chile desde comienzos del siglo XX hasta sus finales, donde la perspectiva americanista transitó desde un nacionalismo criollo hasta el concepto de americanismo universal, vemos que, a pesar del conservadurismo de la sociedad chilena, los compositores lograron establecer ciertos hitos de vanguardia musical en el continente. Estos hitos se muestran con claridad en las nuevas sonoridades que hoy nos acompañan y que se han hecho parte de los cambios políticos y culturales de nuestro territorio y de toda Latinoamérica, desarrollo musical que se ha hecho cargo de una estética latinoamericana que sostiene sus valores en la identificación con las músicas nacionales tanto folclóricas, como indígena y criollas. 


\section{Bibliografia}

Castillo Calvo. "Una reflexión desde la historiografía de la composición musical en américa latina, realidad de los (as) compositores (as)" Revista Intersedes Vol 18, No 37, p. 4-5. Web. 18 abr. 2017.

Chase Gilbert. "Recordando a Carlos Vega". Revista musical chilena Vol 12 .Nº61. Web. 28 abr. 1968.

Falabella, Roberto. "Problemas estilísticos del joven compositor en América y Chile". Revista Musical Chilena 12(57): 41-49. Web. 14 may.1958.

González Rodríguez. "Tradición, identidad y vanguardia en la música chilena de la década de 1960". Revista Aisthesis,(38),192-213. Web. 14 dic. 2005.

Ibaceta, Johanna. "Sobre vanguardias musicales en américa latina" Cuadernos del pensamiento latinoamericano $\mathrm{N}^{\mathrm{o}} 17 . \mathrm{p}$ 125- 139. Web.10 dic. 2011.

Torres, R. Memorial de la Asociación Nacional de Compositores, 1936-1986. Santiago: Editorial Barcelona. Web.10 dic. 1988. 